Section Editors

David C. Spencer, MD

Steven Karceski, MD

Noam Saadon-Grosman, Bsc, MSc

Shahar Arzy, MD, MA, $\mathrm{PhD}$

\title{
Virtual reality may relieve pain in patients with spinal cord injury
}

WHAT IS BODY OWNERSHIP? Body ownership is the ongoing feeling that our body and body parts belong to us, and are related to us in a different way than things in the external world. This sense of body ownership may seem trivial to us, yet our brain needs to connect sensory inputs (e.g., touch, pain, and visual information), internal inputs (from our body's internal milieu), and higher cognitive inputs like memories of our body in different events to generate the sense of ownership. For instance, hand ownership is generated by the visual input we get from our eyes that tracks its location, sensory input on its posture (known as proprioception), and the touch of the table that we lean on, as well as our sense of familiarity with our hand and our memories of the hand along our personal history.

\section{WHAT CAN GO WRONG WITH BODY OWNERSHIP?}

What happens when the brain mechanism that creates body ownership fails? In such a state, the brain fails to recognize one's own body (or body part). In this condition, patients often think that their own hand belongs to a visitor or caregiver, or refer to their own hand as an object that is somehow found in their bed, rather than recognizing it as their own hand. This condition often results from a stroke in the right half of the brain. Not only damage to the brain but also damage to the spinal cord or nerves in the body can cause changes in body ownership. Changes in sensory input to the brain can lead to changes in those parts of the brain. ${ }^{1}$ This may further affect body ownership. For example, an arm amputation can result in changes in the brain. Those brain areas previously devoted to the hand may be reassigned to the face. In some cases, these changes lead to chronic pain or other altered sensations in the affected or adjacent body parts.

WHAT IS A BODY ILLUSION? Disturbances of brain, spine, or nerves may affect body ownership in patients. Can we cause such disturbances in healthy people? Studies have shown that body ownership can be manipulated to create different illusions regarding the body and its parts. A famous one is the rubber hand illusion. ${ }^{2}$ In this illusion, a person sits in front of a table and sees a rubber hand instead of his or her own hand (i.e., hidden below the table or behind a curtain). An experimenter strokes the person's hidden hand and the rubber hand at the same time with a small paintbrush. The person sees the rubber hand touched, but feels the touch on his or her real hand. After a while, the person feels as if the rubber hand is his or her own hand; that is, he or she gains ownership of the rubber hand. Studies have shown similar illusions with other body parts (face, nose, leg) and even of the entire body. The illusion is so powerful that brain scans show that areas involved in body ownership are changed while the person comes to believe the rubber hand is actually his or her own hand. ${ }^{3}$ In light of these findings, we may ask whether it is possible to use body illusions to help people who have problems involving body ownership. Specifically, is it possible to alter disturbing sensations in patients, like pain, by alterations of body ownership through illusions? These are the questions addressed by Pozeg et al. ${ }^{4}$ in their study.

HOW WAS THE STUDY DONE? Pozeg et al. tried to modify pain and sensations by modification of body ownership in patients with spinal cord injury. The spinal cord is the main pathway for information connecting the brain and the nerves in the body. Spinal cord injury can cause permanent loss of sensation and movement. The authors used virtual reality (VR) to induce a virtual leg illusion in these patients. Patients sat in their wheelchairs wearing special VR glasses. A computer projected images to the glasses that created a virtual world for the patients. Patients saw a virtual leg, superimposed over their own physical legs. The leg was seen as stroked repetitively in a virtual world, while patients' own legs were stroked at the same time. Because the spinal cord injury prevented patients from feeling touch in their legs, the stroking was applied on the back rather than the legs where sensation remained intact. The authors thought that this illusion of leg ownership might help relieve chronic pain.

WHAT WERE THE RESULTS? The results showed that the leg ownership illusion reduced pain level in patients with spinal cord injury. This effect was seen only when the virtual leg and the patients' back were stroked at the same time, with the virtual 
Figure Virtual leg illusion

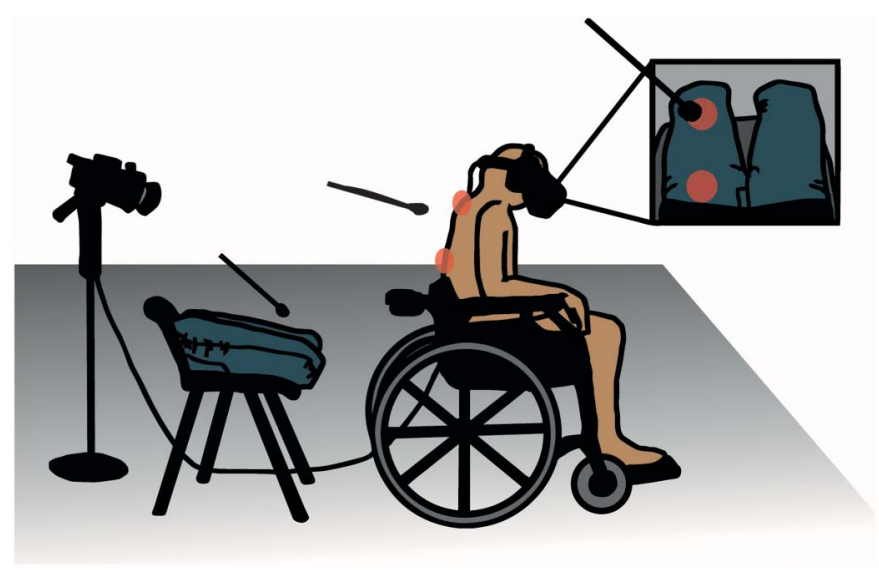

The participant sits in a wheelchair wearing a head-mounted display device that projects real-time video of artificial legs (box). The experimenter sits behind that patient, stroking both the virtual leg and the participant's back at the same time (red dots). The figure is reproduced from the original article. ${ }^{4}$ legs superimposed on the patients' legs. This suggested that the effect was related to body ownership. Both patients and healthy volunteers related the sensory stimulation (in their back) to the visual stimulation (on the leg), as well as a feeling of ownership of the virtual leg. Interestingly, the illusion was weaker in patients than in healthy participants.

WHY IS THIS IMPORTANT? The use of body illusions for pain reduction has a great potential. Our experience with VR as a therapy is just beginning. Advances in technology make implementation of these illusions possible for daily use in various patients. Fascinating and promising as these results are, pain relief in this study was mild. More experiments are needed with new technology before we apply VR in routine clinical practice for this and other neurologic problems. 


\section{PATIENT PAGE}

Section Editors

David C. Spencer, MD

Steven Karceski, MD

Noam Saadon-Grosman, Bsc, MSc

Shahar Arzy, MD, MA, $\mathrm{PhD}$

\section{About spinal cord injury}

THE CENTRAL AND PERIPHERAL NERVOUS SYSTEMS The nervous system is divided into 2 sections. The brain and the spinal cord make up the central nervous system (CNS). Nerve fibers connecting the CNS with other parts of the body are called the peripheral nervous system (PNS). Nerve fibers can go in both directions. Some connect the CNS with muscles to generate movement. Others connect different receptors (i.e., touch, pain, temperature) to the CNS to process sensation.

THE SPINAL CORD The spinal cord is a bundle of nerve fibers that extend from the brainstem to the lower back. It is the main connection between the brain and the rest of the body. The center of the spinal cord contains gray matter (nerve cells) surrounded by white matter (the "wires" that send signals). The front half of the gray matter is called the anterior horn. This is where motor signals are transmitted. The back part is called the posterior horn, where sensory signals are transmitted. Both the anterior and the posterior horns dedicate specific places for different body parts. Specific places are also devoted to specific types of sensation. For instance, information about pain and temperature is carried in the lateral part of the posterior horn. Touch signals run in a tract in the most posterior part. Spinal nerves leave the spinal cord towards the body through nerve roots. These roots carry information between the CNS and the PNS. The spinal cord is surrounded by the vertebral column. It contains 33 vertebrae (bones, part of the skeleton) partially separated by discs. This structure protects the spinal cord and at the same time allows flexibility. Through the vertebrae, 31 pairs of nerve roots exit the spinal cord to form the peripheral nerves. There are 8 at the cervical (neck) level, 12 thoracic (chest), 5 lumbar (lower back), 5 sacral, and 1 coccygeal (tailbone).

WHAT IS SPINAL CORD INJURY? Spinal cord injury (SCI) is damage to part of the spinal cord or nerve roots. SCI usually results in sensory or motor loss below the level of injury. It often results from trauma to the spinal column that fractures or dislocates vertebrae. The displaced bone fragments, disc material, or ligaments damage the spinal cord or nerve root tissue. The exact deficit caused by SCI varies. It depends on the specific location of the injury the tracts involved. SCIs are classified as either complete or incomplete. Patients with incomplete injuries retain some motor or sensory functions below the injury, signifying that information transmission through the spinal cord is not completely lost. A complete injury leads to a total lack of sensory and motor function below the level of injury. Patients with a complete cervical (neck) SCI will have paralysis and loss of sensation in all limbs and the trunk. Patients with a lower SCI may have problems only in the lower limbs and trunk. Importantly, the parts of the spinal cord that control bowel and bladder function run in the middle of the spinal cord. Therefore, complete SCI often involves difficulties in emptying or storing contents in the bladder and bowel. Finally, SCI may cause immense pain, most often due to pressure of disc material on nerve roots.

WHAT ARE THE AVAILABLE AND FUTURE TREATMENTS? An emergency surgical repair may save the affected spinal cord tissue. It is the treatment of choice in trauma settings as well as in injury that causes incontinence. Surgical repair is also used when a motor deficit is caused by a reparable pressure on the spinal cord, or to relieve intolerable pain. Most SCI patients undergo rehabilitation that includes physical training, skill building activities, and mental support. Some impairments may be treated by medications such as muscle relaxers.

Future treatments that are being studied include bypassing a spine injury by electrically connecting an artificial body part directly to the brain. A powered exoskeleton is a solution that is already in use. The current work of Pozeg et al., together with other new technological developments in the fields of virtual and augmented reality, open a new avenue for treatments for patients with SCI.

\section{REFERENCES}

1. Saadon-Grosman N, Tal Z, Itshayek E, Amedi A, Arzy S. Discontinuity of cortical gradients reflects sensory impairment. Proc Natl Acad Sci USA 2015;112:16024-16029. 
2. Botvinick M, Cohen J. Rubber hands "feel" touch that eyes see. Nature 1998;391:756

3. Ehrsson HH, Spence C, Passingham RE. That's my hand! Activity in premotor cortex reflects feeling of ownership of a limb. Science 2004;305:875-877.

4. Pozeg P, Palluel E, Ronchi R, et al. Virtual reality improves embodiment and neuropathic pain caused by spinal cord injury. Neurology 2017;89:1894-1903.
FOR MORE INFORMATION

The National Institute of Neurologic Disorders and Stroke

ninds.nih.gov/Disorders/All-Disorders/Spinal-Cord-Injury-InformationPage

Mayo Clinic

mayoclinic.org/diseases-conditions/spinal-cord-injury/basics/definition/ con-20023837

eMedicine

emedicine.medscape.com/article/793582-overview 


\section{Neurology}

\section{Virtual reality may relieve pain in patients with spinal cord injury \\ Noam Saadon-Grosman and Shahar Arzy \\ Neurology 2017;89;e227-e230 \\ DOI 10.1212/WNL.0000000000004592}

This information is current as of October 30, 2017

\section{Updated Information \& Services}

References

Subspecialty Collections

Permissions \& Licensing

Reprints including high resolution figures, can be found at: http://n.neurology.org/content/89/18/e227.full

This article cites 4 articles, 3 of which you can access for free at: http://n.neurology.org/content/89/18/e227.full\#ref-list-1

This article, along with others on similar topics, appears in the following collection(s):

All Spinal Cord

http://n.neurology.org/cgi/collection/all_spinal_cord Spinal cord trauma; see Trauma/spinal cord trauma

$\mathrm{http} / / /$ n.neurology.org/cgi/collection/spinal_cord_trauma-see_trauma-s pinal_cord_trauma

Information about reproducing this article in parts (figures,tables) or in its entirety can be found online at:

http://www.neurology.org/about/about_the_journal\#permissions

Information about ordering reprints can be found online: http://n.neurology.org/subscribers/advertise

Neurology ${ }^{\circledR}$ is the official journal of the American Academy of Neurology. Published continuously since 1951, it is now a weekly with 48 issues per year. Copyright (O 2017 American Academy of Neurology. All rights reserved. Print ISSN: 0028-3878. Online ISSN: 1526-632X.

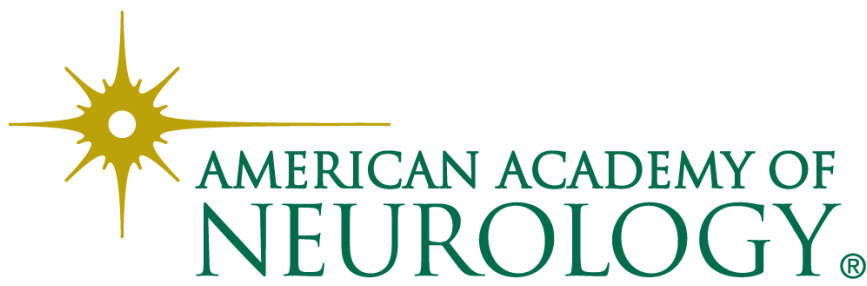

